\title{
Educação Ambiental: uma prática interdisciplinar
}

\section{Environmental education: limits and possibilities to an interdisciplinary pratice}

\author{
Maria do Rosário KNECHTEL*
}

\begin{abstract}
RESUMO
Este texto traz primeiramente, algumas premissas teóricas e fundamentos que possibilitem construir uma prática interdisciplinar em Educação Ambiental, a partir de ações integradas entre a pesquisa e o ensino. Em um segundo momento, apresenta a prática interdisciplinar implementada no Curso de Doutorado em Meio Ambiente e Desenvolvimento, da Universidade Federal do Paraná (UFPR), Brasil, na disciplina Educação Ambiental; trata-se de uma proposta de atividade para a construção e reconstrução do conhecimento, a qual desencadeia uma interação de disciplinas das áreas de Ciências Sociais e Naturais, em uma prática de ensino e pesquisa coletiva. As idéias e a prática desenvolvidas têm como base experiências com a metodologia da Problematização, realizadas por Maguerez (BORDENAVE; PEREIRA, 1982); Berbel (1994) e Knechtel (1998). A fundamentação se apoia em Leff (1995); Piaget (1970); Vygotski (1988); Floriani (1998-99); Medina (1997); Fazenda (1995-97); Vásquez (1977); Fourez (1995), entre outros.
\end{abstract}

Palavras-chave: prática interdisciplinar, metodologia da problematização, ensino e pesquisa, educação ambiental e construção de conhecimento

\begin{abstract}
This text aims first at presenting some theoretical premises and fundaments that allow for the construction of an interdisciplinary practice in Environmental Education by means of integrated actions between teaching and research. Secondly, the interdisciplinary practice implemented in the Doctorate in Environment and Development from the Federal University of Paraná, Brazil, is presented in the Course of Environment Education. The proposed activity concerns the construction and reconstruction of knowledge and brings up an interaction between de Courses in the fields of Social and Natural Sciences, allowing for a joint practice of teaching and research. The ideas and practices developed are based on experiences with problematics methodology conducted by Maguerez (BORDENAVE; PEREIRA, 1982); Berbel (1994) and Knechtel (1998). The fundamental is supported by Leff (1995); Piaget (1970); Vygotski (1988); Floriani (1998-99); Medina (1997); Fazenda (1995-97); Vásquez (1977); Fourez (1995), among others.
\end{abstract}

Key-words: interdisciplinary practice, problematics methodology, teaching and research, environmental education and knowledge construction

* Doutora em Sociologia da Educação, Professora do Curso de Doutorado em Meio Ambiente e Desenvolvimento - UFPR, responsável pela disciplina Educação Ambiental. 


\section{Introdução}

A análise dos problemas socioambientais sinaliza que tentar reverter suas tendências não será possível sem a reconstrução dos conhecimentos, valores e atitudes que configuram a racionalidade social atual.

Daí a necessidade da tomada de uma consciência social mais incisiva pelos docentes e pesquisadores sobre problemas ambientais para a construção de novos conhecimentos, métodos e práticas educativas na formação profissional. Isto constitui um dos desafios mais importantes para a educação superior deste novo século e só será possível mediante novas práticas, novos agenciamentos do conhecer.

$\mathrm{O}$ interesse em trabalhar uma prática interdisciplinar como Metodologia do Ensino no Curso de Doutorado em Meio Ambiente e Desenvolvimento, priorizando a formação do profissional de nível superior em questões ambientais e de desenvolvimento social, incide sobre o ensino pela pesquisa, como também, sobre a pesquisa para o ensino. Desta forma, acreditamos ser possível construir e reconstruir conhecimentos, ${ }^{1}$ buscar respostas e até propostas de solução, pela interação de alunos e professores com o saber ambiental - não como uma nova disciplina, já que não é só uma disciplina que determina todo o saber, nem com a introdução da Ecologia, cuja matéria, às vezes, é simplesmente incorporada aos conteúdos curriculares, senão como uma práxis educativa que trata do saber emergente que concentra todas as disciplinas em todos os níveis do sistema educacional (LEFF, 1995), resgatando o humano, o ético, o natural, no ato pedagógico.

O saber ambiental problematiza a construção do conhecimento, discute a necessidade de legitimá-lo e institucionalizá-lo, abrindo espaços para a investigação e a formação de profissionais em meio ambiente, nas universidades. Isto supõe novos objetivos para a educação superior na perspectiva do desenvolvimento sustentável, com a produção de um saber ambiental que possa ser incorporado às novas estruturas curriculares e práticas educativas. Formar um novo profissional com visão de mundo e preparação teórico-prática para abordar os problemas ambientais da sua disciplina (LEFF, 1995), é tarefa primordial da universidade.
Para tanto, perguntamos: como viabilizar a incorporação da dimensão ambiental nas universidades?

Como a prática interdisciplinar, apoiada na Metodologia da Problematização, pode ser uma alternativa metodológica de ensino e de pesquisa para a construção do conhecimento, no sentido de preparar o profissional que lida com as questões educacionais e ambientais, para melhor atuar em seu meio?

Como, pois, articular os distintos "saberes" disciplinares dos doutorandos em uma ação também articulada e coordenada, com garantia da contribuição de cada um deles, para a construção do conhecimento na área em foco?

\section{Fundamentos para uma prática interdisciplinar}

Em busca de sustentação para as perguntas levantadas, logo deparamos, em princípio, com o documento da Conferência Mundial de Educação Superior (Paris, 1998), cujo artigo 5, letra a, sugere:

O progresso do conhecimento mediante a investigação é uma função essencial de todos os sistemas de educação superior que têm o dever de promover os estudos de pós-graduação. Deveriam reforçar a inovação, a interdisciplinaridade, a trandisciplinaridade nos programas, fundando as orientações a longo prazo com objetivos e necessidades culturais e sociais (UNESCO, 1998).

Nesse sentido, também se manifesta Leff (1995) ao afirmar: "É necessário concentrar esforços na formação de professores e pesquisadores, incluindo processos de autoformação e estratégias para elaborar conteúdos curriculares integrados." Acreditamos, conforme sugere o referido autor, que, para a educação formal, será um válido caminho "o estabelecimento de seminários permanentes de professores para discussão, criação e avanços de novos métodos, de práticas e conhecimentos ambientais." O aperfeiçoamento de conteúdos curriculares e de práticas sociais e pedagógicas inovadoras nos cursos superiores, poderá ser alcançado com a práxis pedagógica, propugnando indissociabilidade entre ensino e pesquisa. A práxis, por

1 Neste artigo, entende-se que construir conhecimento significa produzir algo diferencialmente novo; e reconstruir significa compreender e interpretar sob novas bases epistemológicas. 
meio da investigação e do ensino, remete o professor às atuais dificuldades educacionais e suas confrontações, destacando-se aí um ponto crucial: o da prática pedagógica interdisciplinar. Estudos sobre esta prática, como os de Fazenda (1998), de Lück (1995) e outros, têm privilegiado estas discussões, com a pretensão de alcançar uma prática pedagógica interdisciplinar de qualidade, ${ }^{2}$ entretanto, os resultados alcançados ainda são pequenos. $\mathrm{O}$ fato de não existir uma disciplina específica para tratar as questões ambientais, faz com que uma proposta interdisciplinar venha - com maior razão - ao encontro das necessidades da educação que leva em conta o ambiente.

As práticas educativas ambientais, todavia, se desenvolvem no âmbito universitário, ligadas a modelos disciplinares, a docentes de áreas como a biológica, a química e outras. Os poucos resultados obtidos repousam no fato de que a prática interdisciplinar, não tem sido suficientemente compreendida.

Neste sentido, a análise passa necessariamente por duas vertentes, não dicotômicas, mas sim complementares. A primeira, ontológica, isto é, a que reflete sobre $o$ ser e, a segunda, que discute a dimensão pedagógica e a prática interdisciplinar na formação de sujeitos-educadores ambientais. E, destas duas vertentes, o nascedouro de um conceito aberto da Educação Ambiental, como um dos meios de mediação de possíveis transformações.

\section{A crise do ser e do pensar}

Como resultado de discussões e reflexões críticas para a reconstrução do conhecimento em Educação Ambiental, trazemos a reconstrução e interpretação do discurso de Leff (1999). Resumidamente, partimos do pensar a crise, a complexidade ambiental, procurando respostas a perguntas fundamentais: que é ambiente? Que é educar? Como profissionalizar o educador ambiental?

"Há um mal estar da cultura" Leff (1999). ${ }^{3}$ É preciso pois, refletir sobre $o$ ser, sobre sua relação com o conhecimento que constrói e que se legitima pela cultura.

Então, a crise ambiental, é crise também do conhecimento, pois desconstruímos o que já construímos - é o desconhecimento da natureza:
O mundo vem se complexificando e não é só o paradigma holístico ou o sistêmico que vai resolver a crise ambiental. Hoje, temos que estudar a falta do Ser - de um vir-a-ser, cheio de incertezas. Não se pode resolver tudo com uma questão racial. A crise ecológica é também a falta de conhecimento da natureza; é a crise do Ser e do pensar (LEFF, 1999).

Se não somos capazes de fazer a reflexão sobre $o$ ser, a natureza, a educação e a cultura, a conseqüência "é a crise ambiental" (LEFF, 1999). Este espaço forjará o conhecimento próprio da diversidade cultural que temos; "um espaço reconstruído coletivamente, com o desejo de não nos ajustarmos ao imposto, para não sucumbirmos é o que temos de perseguir."

Estamos pensando na construção de um saber novo - o saber de um novo ser -, apoiado não somente nos saberes acadêmicos, mas numa construção coletiva de Educação Ambiental que mobilize os saberes comunitários locais, regionais e socioculturais. Este poderá trazer as formas do ser do passado, as identidades das pessoas com que trabalhamos; a identidade de processos, de modos de vida, de participação democrática, de como se planificam e se organizam estas participações coletivas para produzir o novo, a transformação.

Trata-se de um processo de recuperar suavemente a propriedade dialógica, o saber aprender, aprender com o outro, não só nos livros: aprender observando, na convivência com o outro. É a "Pedagogia de deixar ser", é a Pedagogia da esperança" (LEFF, 1999; FREIRE, 1994). Estamos lidando com contradições entre o real e o ideal, e não somente com um problema de espaço ambiental, mas com o tempo da discussão, da reflexão e da ação.

O ambiente, como objeto do conhecimento, é um saber que não está feito, tem que ser construído, "não está dado", é uma questão ontológica; e temos que construí-lo na convivência com o outro. É preciso observar o ambiente como ser construído. Somos seres humanos, seres simbólicos, o que nos remete à crise do conhecimento. Os problemas são de tal magnitude que exigem uma força maior. Que dizer, então, sem a reflexão? Confrontar os saberes interdisciplinares, como? Se alguém não leu e, às vezes, nada sabe sobre isso ou aquilo?

2 Temos acompanhado e percebido as inúmeras reclamações e alertas da Coordenação de Educação Ambiental do Ministério de Educação e Cultura e das Unidades Estaduais do Meio Ambiente, quanto às limitações evidentes na implantação de programas desta área atribuídas à falta de profissionais preparados (MEC, 1997/98) .

3 Conferência Magna do Congresso de Educação Ambiental em Havana. Participação da autora em 1999. 
O futuro é mais do que nunca um desafio, neste mundo dominado pelo capital e pela lógica do mercado, os quais não garantem um mundo sustentável.

Uma Educação Ambiental interdisciplinar, com a possibilidade da transversalidade no currículo, na qual muitos educadores estão envolvidos, segundo o mesmo autor, não mais dará conta, da problemática posta, pois não se trata só de resolver questões com saberes já dados. Esta interdisciplinaridade parece não bastar. Os conceitos fundamentais devem ser construídos e não apenas dados. Devem processar-se numa abertura de saberes que não se formalizam, que estão abertos à diversidade cultural, às diferentes formas de ser e não à homogeneização de um poder de sustentabilidade que busca seduzir e recodificar os valores no mundo do mercado.

"O ser humano se constitui, então no limite, na morte? Não é a política de domínio da globalização que vai solucionar todas as dimensões da crise" (LEFF, 1999). Só podemos buscar soluções pensando, refletindo, educando, criando. E, para isto, muito pode contribuir uma Educação Ambiental permanente e aberta, que privilegie as práticas socioeducativas interdisciplinares, seja na educação formal ou não-formal.

De fato, entra em questão uma rede de formação ambiental, como um espaço cognitivo cuja base é a reflexão ambiental que constrói o conhecimento, com a participação de diferentes sujeitos de culturas diversificadas; seria uma alternativa de solução aos problemas da ampla crise da qualidade de vida, no contexto da Educação Ambiental, necessariamente em interação com as demais ciências.

\section{A dimensão pedagógica e a prática interdisciplinar}

De modo geral, as práxis desenvolvidas no ensino superior relacionadas com a Educação Ambiental não se configuram como práxis reflexivas, criativas, marcadas por um alto grau de consciência acerca de seus determinantes, de suas limitações e função social; e é este um dos fatores que provavelmente impedem a superação das limitações da Educação Ambiental. Talvez se expliquem, estas limitações pelos limites mesmos da relação entre ensino e pesquisa. Esta relação pressupõe o ato pedagógico que é composto por dois sujeitos: aluno e professor, mediados pela prática de ensino e da pesquisa.

Ensinar e aprender são processos complementares; logo professor e aluno, cada qual com sua cultura, sua his- tória e seus saberes necessitam estar juntos para garantir o espaço de cada um deles, na construção e reconstrução do conhecimento. É como um ato de criação do conhecimento, que acontece pelo exercício de pensar, de agir e de sentir juntos. Nesse ato há que existir um só eixo: ensinar pela pesquisa e pesquisar para o ensino; pesquisa-se o ensino e ensina-se por meio da pesquisa; entendemos pois, a aprendizagem enquanto processo individual e social, com ênfase ao movimento da prática e da relação desta com os conhecimentos a serem criados (construídos, produzidos).

E quais são pois, as relações que a Metodologia do Ensino (inserida nela a prática interdisciplinar), estabelece com a Epistemologia e a Metodologia de Pesquisa?

A Epistemologia é o conhecimento do conhecimento enquanto objeto questionado; a Metodologia da Pesquisa é a busca de formas, de instrumentos, de caminhos para o conhecimento. Então, o que cabe ao ensino? É um conjunto de procedimentos, de técnicas, de práticas, de maneiras, de posturas e de recursos auxiliares orientados a um determinado fim; e neste caso, a um fim educativo ambiental.

A pesquisa, por sua vez, constitui também um conjunto de procedimentos humanos e técnicos para a leitura e a construção teórica de uma realidade. Ela implica relações íntimas, estabelecidas pela rede de interações, constituída pelo sujeito e objeto da investigação. É oportuno lembrar aqui que

A questão da interdisciplinaridade emerge também como orientação da superação da dicotomia entre Pedagogia e Epistemologia, entre ensino e produção de conhecimentos científicos; é a razão da maior complexidade e necessidade de superação da perspectiva fragmentadora do ensino (LÜCK, 1994).

No ensino, as duas metodologias, a de investigação e a de ensino, se não se confundem, se compreendem e se aproximam, possibilitando interfaces. Ambas constituem

\begin{tabular}{|c|c|c|}
\hline EPISTEMOLOGIA & ENSINO & PESQUISA \\
\hline $\begin{array}{l}\text { Construção de pres- } \\
\text { supostos e } \\
\text { bases do conheci- } \\
\text { mento pedagógico }\end{array}$ & $\begin{array}{l}\text { Construção peda- } \\
\text { gógica do conhe- } \\
\text { cimento organi- } \\
\text { zado metodolo- } \\
\text { gicamente }\end{array}$ & $\begin{array}{l}\text { C on s t r u çã o } \\
\text { metodológica do } \\
\text { conhecimento } \\
\text { para a pesquisa } \\
\text { no ensino }\end{array}$ \\
\hline
\end{tabular}

FONTE: BECKER, 1998. 
processos e não produtos. As interfaces do processo pedagógico podem ser assim configuradas:

O enfoque interdisciplinar dentro do contexto educacional, torna-se uma imprescindível contribuição à reflexão e ao encaminhamento de soluções das dificuldades referentes à investigação e ao ensino e para a reconstrução do conhecimento.

Deste modo, forma e contexto se apresentam no mesmo processo, rompendo com a linearidade da causa e efeito. Fora deste entendimento o conhecimento fragmentado ainda continua sendo produzido dissociado ou fragmentado do conhecimento do contexto, de onde emerge e cria um conhecimento limitado. Assim, um conjunto de conhecimentos paralelos, desconectados uns dos outros, são aceitos como legítimas representações da realidade.

Aqui consideramos imprescindíveis as ações integradas entre a pesquisa e o ensino, bem como a dinâmica das interações entre as ciências sociais, as pedagógicas e as da natureza em Educação Ambiental. Isto nos leva à busca de processos e fundamentos teóricos, a partir de certezas, de críticas, de possibilidades e limitações, o que vem explicitado mais adiante.

Um profissional de educação ambiental, crítico e reflexivo, terá que incorporar em seus conhecimentos, as questões ambientais atuais e a prática interdisciplinar. Assim, a complexidade das relações homem/natureza, ou sociedade/natureza, no processo de desenvolvimento contemporâneo, ou seja, as inovações tecnológicas, o crescimento das cidades, a descoberta da finitude da riqueza e, paralelamente, a degradação do ambiente com a ameaça de falência dos recursos naturais, em especial da água, estão a exigir estudos e práticas interdisciplinares. Embora estes fenômenos estejam correlacionados historicamente, evidenciam-se situações conflituosas entre as lógicas que deles decorrem, estabelecendo restrições à sua própria sustentabilidade e manutenção.

Percebemos, todavia, claramente, a alienação do ensino acadêmico, ainda tradicional e com disciplinas compartimentalizadas que, às vezes, nem ao menos interagem teoricamente para melhor compreender as diversas racionalidades subjacentes aos processos de desenvolvimento e a conseqüente degradação ambiental.

Para a compreensão das contradições que emergem do processo como um todo, necessitamos da pesquisa articulada ao ensino, bem como do estudo, da interpretação dos fenômenos por profissionais, nos vários campos do conhecimento: do economista, do arquiteto, do agrônomo, do urbanista, do geógrafo, do engenheiro, do sociólogo, do advogado e, entre outros, também do educador. Não é da justaposição, mas da integração destes saberes, da criação de estratégias de prevenção e de práticas sociais educativas, que se fará possível a transformação de atitudes nas relações sociedade/natureza com base na ação-reflexão-ação (VASQUEZ, 1977). Então, para o desenvolvimento da percepção interdisciplinar dos processos até aqui mencionados, pressupomos um profissional de meio ambiente, ou educador ambiental, que integre ao ato pedagógico a pesquisa oriunda de necessidades de descobertas, das dinâmicas interativas e de atitudes desencadeadas para o exercício da prática interdisciplinar.

Como se vê, a Educação Ambiental não é um campo homogêneo, unidimensional; nem pretendemos que o seja, pois a realidade que enfrentamos não é também homogênea, tão pouco de uma única dimensão.

Para esta profissionalização defrontamo-nos com diferentes leituras políticas, econômicas, socioculturais, de espaços diversos, porém com os mesmos problemas. Não há ainda um referencial paradigmático e nem valores consensualmente consolidados e eticamente propostos, em ação, capazes de promover práticas interdisciplinares pertinentes à esfera da Educação Ambiental; há, sim, diferentes concepções sobre a educação e o ambiente. Discursos conservadores começam a ser questionados e discursos alternativos, interdisciplinares buscam rearticular o campo da Educação Ambiental.

Contradições reinantes refletem posições diversas como analisa Huckle (1996, apud GAUDIANO, 1998): "Existe uma contradição nodal entre a sustentabilidade 'débil' defendida pelos reformistas liberais e social-democratas e a sustentabilidade 'forte' pela qual advogam os socialistas verdes e os utópicos radicais." Leituras mais recentes mostram que não se chegou ainda a uma postura capaz de superar as formas de intervenção pedagógica que aí estão, frente ao conflito ambiental (LEFF, 1998-99; GAUDIANO, 1998-99; MEDINA, 1998-99, 2000).

Ante este estado de coisas, da problematização à busca de alternativas de solução, emergem muitos questionamentos como: aonde nos conduz todo este quadro? Como superar nossas deficiências teórico-práticas? Como melhor aproveitar as contradições neste campo? Onde buscar os fundamentos que darão sentido "definido" aos processos da profissionalização dos educadores ambientais?

Sobre uma possível relação ideal entre a sociedade, o meio ambiente e a educação, procuramos construir um 
conceito numa perspectiva aberta e interdisciplinar, segundo o qual,

a educação ambiental é uma prática educativa inserida em um projeto político-pedagógico associado a uma concepção de mundo. Decorre de um projeto sociocultural implicando: a) o reconhecimento das necessidades das pessoas; b) os valores axiológicos que as formam e a permanente busca de qualificação dessas pessoas para que enfrentem as questões de seu contexto sócio-histórico-ambiental. ${ }^{4}$ relevantes:

Esse processo é complementado por dois aspectos

I - a educação instrumentaliza os jogos de relações entre os interesses do indivíduo e os interesses da coletividade;

II - a Educação Ambiental se refere a um jogo de interesses específicos em que dimensões e dinâmicas temporais, espaciais e culturais compreendem, desde o nível local até o nível planetário, [às condições de vida].

No presente conceito construído, está implícita uma visão de mundo e de sociedade ligada aos projetos humanos subjacentes a essa construção. Não deixam de ser uma tentativa de entendimento a múltiplas legitimações. Pretende ser o momento ou o ponto de um desenvolvimento histórico contingente (FOUREZ, 1995).

Tal conceito de Educação Ambiental está aberto, não é dado de uma vez por todas. Encontra-se ligado às culturas, uma vez que, tal conceito não aparece pronto: é construção ligada à cultura, à iniciação de novos modos de vida.

A educação como processo do contexto social, precisa integrar-se ao todo deste contexto; não como repetidora de conceitos, mas como propulsora de análise crítica e da atuação interdisciplinar para buscar o resgate da dimensão humana relações do homem com a natureza. Esse movimento deve ir além de simples palavras; e, sim provocar uma nova postura, um novo agir e uma prática socioeducativa.
Todavia, parece que a interdisciplinaridade só acontece quando houver interesse do pesquisador. Costuma-se contrapor problemas e tensões que surgem nos grupos de pesquisa "muito mais devido ao perfil dos pesquisadores do que das clivagens disciplinares" (MUXART et al., 1992; BRANDENBURG, 2000).

Há que se criar uma força aglutinadora, uma certa "ideologia" da interdisciplinaridade para a interação entre os pesquisadores, alunos e demais envolvidos (BRANDENBURG, 2000).

A interdisciplinaridade é uma

questão de atitude, uma construção que parte, primeiro de uma conversão pessoal e experiência de vida, para então partilhar o conhecimento específico com o conhecimento do grupo (WACHOWICZ, 1998). É o processo que parte do multidisciplinar em busca da construção da interdisciplinaridade (MEDINA, 1997, KNECHTEL, 1998).

Entendendo, pois, interdisciplinaridade, como um processo aberto em elaboração e que permite a construção de metodologias, valêmo-nos da contribuição de Fourez (1995, p. 134-137), que qualifica com clareza a abordagem interdisciplinar enquanto prática, a fim de facilitar a compreensão da prática interdisciplinar na Educação Ambiental. ${ }^{5}$

Referindo-se à complexidade dos problemas e à necessidade de busca de outros enfoques, afirma o autor: "Cada vez mais se admite que, para estudar uma determinada questão do cotidiano, é preciso uma multiplicidade de enfoques. E a isto alude o conceito de interdisciplinaridade" (FOUREZ, 1995, p. 134).

No entanto, na prática, este conceito oculta duas perspectivas. Na primeira, uma abordagem interdisciplinar pretende construir uma nova representação do problema, independentemente de qualquer critério particular - será uma superciência? O próprio autor questiona.

$\mathrm{Na}$ mesclagem de diferentes disciplinas, de maneira sempre particular, obtemos um enfoque original. Por exemplo: a degradação da água é examinada, avaliada por um maior número de disciplinas, nos vários aspectos do problema. Isto gera apenas um novo enfoque original, um novo paradigma, apresenta até um progresso em relação às dis-

4 Este conceito tem base em construção coletiva da Turma II do Curso de Doutorado em Meio Ambiente - UFPR - 1997.

5 Este conceito é resultado de construção coletiva dos estudantes no seminário interdisciplinar, realizado com turma II (1997). 
ciplinas anteriores, mas não cria uma superciência (FOUREZ, 1995, p. 135).

Na segunda perspectiva, o autor descarta a idéia de superciência. A interdisciplinaridade não se destina a criar um discurso novo para além das disciplinas particulares. Ela é uma prática específica cuja abordagem está relacionada com os problemas do cotidiano; é uma prática essencialmente política que implica discussão, reflexão e negociação entre diferentes pontos de vista para decidir sobre a representação mais adequada à ação (FOUREZ, 1995, p.136). Por exemplo, numa comunidade molestada por poluição sonora, ou de gases, ou má qualidade de água: os pesquisadores podem buscar especialistas não para criar uma nova disciplina científica, e sim para resolver um problema concreto, apoiado nos diferentes saberes.

$\mathrm{Na}$ primeira perspectiva, ao relacionar disciplinas num processo neutro, poderão ocorrer dissimulações por meio de questões próprias da interdisciplinaridade como: quais especialistas serão consultados, quais disciplinas são as mais importantes? Como tomar decisão concreta? Estas tensões mascaram a abordagem interdisciplinar, prejudicando a construção do conhecimento pretendido?

O entendimento da interdisciplinaridade é enfatizado como prática política, segundo Fourez (1995); e este pressupõe a práxis, a ação-reflexão-ação. $\mathrm{O}$ autor dá destaque à prática política que aceita confronto de diferentes olhares para uma tomada de decisão conseqüente, não só de conhecimentos construídos mas de riscos assumidos ética e politicamente.

A prática interdisciplinar, assim compreendida, aceita conseqüências; e, dos confrontos, das ações e das análises, ela não se pode deduzir uma racionalidade universal; é resultado de múltiplas interações "aproximando-se mais do modelo sociopolítico do que da representação de uma racionalidade universal. Isto é válido tanto para o trabalho disciplinar quanto à prática interdisciplinar." (LATOUR WOLGAR, 1981; LATOUR, 1984; PANDORE, 1982, apud FOUREZ, 1995, p. 137).

Acreditamos que a prática interdisciplinar para a Educação Ambiental, apoiada em fundamentos da práxis que a privilegiem como prática política, como prática social-educativa, oferece-nos mais aproximações e possibilidades de reeducação de uns com os outros, para e pela construção do conhecimento interdisciplinar, do que no ensino tradicional. A interdisciplinaridade exige, tal como no ato pedagógico, imaginação e prática "além de remeter-se concretamente aos desafios que a sociedade lança aos seres humanos, sejam homens e mulheres, sejam alunos e professores em permanente diálogo com a natureza" (FLORIANI, 2000, p. 28).

\section{Alguns pressupostos que orientam a prática interdisciplinar}

A experiência do Doutorado, em Meio Ambiente e Desenvolvimento da UFPR, estudada e analisada por Floriani (1998) "enuncia premissas, com a finalidade de afirmar algumas correções e conquistas práticas, por mais limitadas que possam permanecer em termos de generalização", ainda assim, constituem diretrizes para a construção interdisciplinar. São elas:

- não se faz interdisciplinaridade sozinho; necessitase uma prática coletiva que se oriente à construção de um Programa Comum de Ensino e Pesquisa que privilegie o campo das ciências da vida, da natureza e da sociedade;

- as problemáticas devem convergir para algumas interrogações comuns, articuladas, não homogêneas;

- a interdisciplinaridade em meio ambiente e desenvolvimento deve ser construída na interrelação dos sistemas, social e natural;

- uma prática interdisciplinar não é fechada no tempo. Cada programa pode apresentar novas questões para novas investigações.

Se partirmos da premissa de que, na atividade teórico-prática da educação, no caso da educação ambiental, o trabalho em equipe se constitui como mediação privilegiada para a consolidação da intersubjetividade, podendo ampliar-se quando revestida de rigor, de autenticidade e de compromisso, isto nos mostra possibilidades de construção desta prática interdisciplinar, mesmo que ainda timidamente.

Articulando-nos com os fundamentos de Fazenda (1993) e de Floriani (1998), em relação ao assunto, os pesquisadores ao se referirem a uma necessária "atitude interdisciplinar" dos profissionais, cuja ação, postura e prédisposição, se realizam dialeticamente (isto é, em movimento das situações velhas às novas e destas para as velhas), entendem que a situação antiga da realidade pode transformar-se em nova e que, nesta, se mantém sempre algo do velho. É nesta linha que se harmonizam as premissas sobre a práxis. Essa busca da realidade no movimento dialético é peculiar às práticas interdisciplinares em função do fato de, o tempo todo, levar-nos à realização do 
exercício do diálogo, com nossos próprios "saberes" e outras produções e construções até então existentes de conhecimento; o fim é extrair desse diálogo novas informações, novas premissas que nela ainda não se tinham revelado. Acompanhando este pensar, a "atitude interdisciplinar" supõe um modo de agir que seja garantia de uma atuação mais completa na interação com as dimensões múltiplas das ciências sociais e naturais, no sentido de uma concepção mais realista de suas origens, interrelações e complexidades. Assim essas complexidades envolvidas nas práticas interdisciplinares de Educação Ambiental, nos remetem ao entendimento do que acontece e do que é possível em um "processo multidisciplinar, que busca constituir a interdisciplinaridade" (MEDINA, 1996 apud KNECHTEL, 1997).

\section{Metodologia da problematização: recensão críti- ca e seminário interdisciplinar ${ }^{6}$}

Ao relatar a forma como ocorreram as atividades, é pertinente primeiro esclarecer que foi dada ênfase às pro- blemáticas coletivamente levantadas, observando-se a convergência, frente aos questionamentos comuns, focalizando processos articulados, mas não homogêneos (FLORIANI, 1999).

Os alunos em Doutoramento, com interesses comuns em relação às questões ambientais, porém, com qualificações e saberes diversificados, preservadas as características de heterogeneidade para o estudo nesta área, partiram de um processo de pluralidade, isto é, multidisciplinar, que investiga para produzir conhecimentos centrados na busca da compreensão das interrelações dinâmicas dos ecossistemas considerados como sistemas complexos naturais e sociais.

Para a prática interdisciplinar de Educação Ambiental nos valemos da Metodologia da Problematização (a configurar-se mais adiante) em todas suas etapas, como procedimento acadêmico. Esta preconiza núcleos de estudo e organização de atividades interdisciplinares de ensino e pesquisa ao priorizar o estudo das interrelações complexas nesta área; assim postula uma metodologia multidisciplinar em busca da interdisciplinaridade, orientada para a solução de problemas concretos (MEDINA, 1996, p. 62).

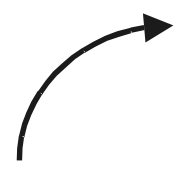

2.0 Pontos chaves ou pressupostos

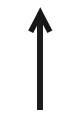

1.0 Observação da realidade (problema)

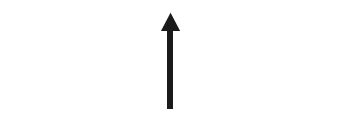

\subsection{Teorização}

Recensão crítica

Seminário interdisciplinar

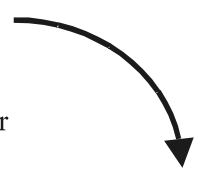

4.0 Alternativas de solução

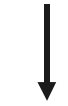

5.0 Aplicação à realidade (prática social)

\section{REALIDADE}

FONTE: KNECHTEL, 1997

\footnotetext{
6 A metodologia da problematização em Educação Ambiental inseriu-se num processo mais amplo articulado às oficinas e aos encontros interdisciplinares com alunos
} e professores do Curso de Doutorado, porém não é abordado aqui o processo metodológico em si mas a prática interdisciplinar vivenciada com a turma II 96/97. 
A metodologia da Problematização (BERBEL, 1994, apud KNECHTEL, 1998) cuja proposta de Maguerez (apud BORDENAVE; PEREIRA, 1982) denominou como Método do Arco e, articuladas a ela, as técnicas de Recensão Crítica e Seminário Interdisciplinar, tem a configuração seguinte:

Para a formação de novos saberes e novos profissionais com uma consciência crítica e reflexiva e uma capacidade de criar alternativas para a solução dos problemas socioambientais, cada vez mais complexos, as disciplinas tradicionais não oferecem resposta, como anteriormente explicitado. Assim, começamos nossa prática, reconhecendo que não é fácil passar da organização de seminários e programas conjuntos, interuniversitários, para a organização de verdadeiros programas de ensino e pesquisa, voltados para a formação de profissionais nesta área.

Inúmeras indagações e reflexões sobre a problemática ambiental emergiram ao longo dos primeiros encontros com os doutorandos. Estes suscitaram ao professor a necessidade de um repensar da prática universitária interdisciplinar a partir da ação-reflexão-ação e, assim, alcançar a construção do conhecimento, sentindo que poderíamos redimensionar e integrar técnicas e métodos de trabalho.

\section{Procedimentos metodológicos}

\section{Observação da realidade}

Reportando-nos à dinâmica de interações vivenciadas pelo grupo de alunos com os demais professores e disciplinas, primeiramente foi lançado um olhar macrosociológico sobre a realidade, seguido de uma pré-leitura inicial com o professor de Educação Ambiental, estreitamente relacionada com problemas sociais, econômicos, demográficos e culturais, determinados historicamente. Houve identificação e enfoque de problemas e estilos de desenvolvimento mal planejados que repercutem significativamente na qualidade de vida da população, tanto no meio urbano como rural e que configuram as diferentes crises nas quais manifesta-se o esgotamento vigente do processo da civilização mundial. Neste sentido, não só perceberam, como suscitaram críticas, no que diz respeito às concepções científicas e tecnológicas, ao nutrir o mito do progresso material ilimitado, mostrando suas limitações éticas e compromissos geopolíticos o que incentiva, de maneira fundamental, os processos de estruturação ambiental.
Prosseguindo, suas observações e reflexões captam e expressam a contradição reinante, articulada aos complexos processos de globalização, onde inúmeros problemas passaram a ser sinalizados por eles. Tendo presente as dimensões: espaço, tempo e movimento, levantaram as problemáticas e as associaram aos sistemas. Entre elas:

- a subordinação política e econômica dos povos, em tempos de expansão e amadurecimento democrático;

- a fragmentação étnica;

- as tendências à homogeneização cultural;

- políticas e ideologias hegemônicas, impulsionadas pelos países industrializados;

- dominação de organismos financeiros internacionais internacionais;

- crise ecológica;

- problemática ambiental requerendo novas perspectivas de preservação e de desenvolvimento, manutenção dos núcleos vitais da natureza;

- incremento aos níveis de bem-estar à maioria da população;

- aprofundamento do estudo dos fenômenos e processos de degradação ambiental ao caráter local, regional e planetário;

- planificação e gestão ambiental;

- metropolização;

- qualificação de profissionais para abordagem técnico-científica das questões ambientais; marcos conceptuais e históricos de diversos momentos, apropriados de realidades particulares e a construção de horizontes para o futuro.

Em seguida, na primeira oficina de pesquisa discutiram e fizeram correlações com a realidade paranaense; no caso a Região Metropolitana de Curitiba, onde foram identificados e formulados os problemas ambientais regionais e depois os locais, buscando-se soluções. Desenvolvendose, depois a problematização propriamente dita, isto é a problematização como método de ensino e pesquisa, ou seja, como exercício acadêmico e social.

Nesta fase uma primeira "leitura" da realidade de Curitiba suscitou coletivamente, a pesquisa básica. Utilizaram fontes secundárias dos diferentes atores sociais, resgatando dados e situações-problema nas diferentes dimensões e sistemas, correlacionando-os. Dos problemas que circundam a capital paranaense, destacam-se:

- contradições nas relações sociedade/natureza;

- produção, apropriação e uso indevido da natureza para desenvolvimento industrial; 
- transformação do espaço social-urbano em cujo plano, os pressupostos humanos e sociais são em níveis secundários, considerados e evidenciados;

- frágil interação entre os segmentos socioambientais, culturais, tecnológicos e políticos, envolvidos no desenvolvimento urbano da metrópoles etc.

Numa ação conjunta, os estudantes definiram seguidamente aqueles problemas considerados como prioritários e viáveis de um estudo mais profundo. Discutiram e elegeram critérios de seleção, estabelecendo as lógicas de pensamento, ação e construção a serem trabalhados do ponto de vista da pesquisa e da prática interdisciplinar. Os problemas considerados prioritários foram:

- qualidade de vida em Curitiba: essência e aparência (1970-1995);

- a produção do espaço na Região Metropolitana de Curitiba (RMC);

- gestão ambiental e qualidade de vida no trabalho em empresas do setor produtivo da RMC, um estudo comparado;

- gravidez na adolescência e urbanização da RMC;

- políticas e práticas de gestão ambiental na RMC;

- sistemas de informação e tomadas de decisão ambiental na RMC: a gestão da água;

- critérios de sustentabilidade: subsídios para o desenvolvimento agrícola sustentável da RMC;

- planejamento urbano ambiental: o caso da RMC;

- gestão participativa de recursos hídricos: estudo de caso da desembocadura do Alto Iguaçu;

- estratégias de desenvolvimento sustentável em sistemas urbanos complexos;

- família, trabalho e pobreza: elementos para a compreensão das condições de vida e ambientais resultantes do processo de metropolização da RMC;

- construção de uma proposta curricular para a formação de formadores em educação ambiental e sugestões até para um curso de especialização.

\section{Pontos-chave}

A problematização, vivenciada na oficina II gerou três focos: a metropolização, o ambiente e o desenvolvimento, em consonância com a área de concentração e as linhas de pesquisa do curso. ${ }^{7}$ Ao buscar os pontos-chave da pesquisa sobre a Região Metropolitana, explicitaram-se as lógicas daí decorrentes, tentando-se construí-las num processo interdisciplinar:

- a lógica das Políticas Públicas, que passa a compreender: problemas relacionados a Políticas Públicas (federal, regional, e locais), de Gestão, Monitoramento, Questão Florestal, Planejamento Urbano (Educação e Saúde);

- a lógica da Produção abrangendo: Agricultura/ Meio Rural - Indústria - Pobreza e Mercado de Trabalho - Apropriação Espacial;

- a lógica dos recursos referentes aos Recursos Hídricos - Saúde e Educação.

A problematização e identificação dos pontos-chave provocou, uma lista de questionamentos oriundos do grupo:

- quais as principais causas do problema?

- quais são suas possíveis determinantes contextuais?

- quais são seus componentes e seus desdobramentos?

- que opções e interrelações disciplinares poderão acontecer? Quais são as mais viáveis?

- de que maneira argumentar e construir o caminho para a pesquisa? (conformá-lo ou modificá-lo?)

- como realizar a intercomunicação entre a lógica de uns e de outros?

- como construir interdisciplinarmente um quadro teórico-conceptual, referente aos problemas selecionados?

- como encontrar hipóteses de solução?

Não temos a pretensão de colocar aqui as hipóteses de todos os problemas levantados e que ainda estão sendo objeto de teses dos doutorandos. A partir daqui, no desenvolvimento da disciplina Educação Ambiental centramonos em sua temática, especialmente na formação de profissionais para esta área. Foram assim formuladas as hipóteses em busca da perspectiva teórica:

- frente aos desafios da contemporâneidade na educação e, em particular na Educação Ambiental, pode constituir-se uma prática interdisciplinar permanente, para a construção de novos saberes ambientais em nível da Região Metropolitana de Curitiba? 
- é possível, com base nas concepções socioambiental, sociocultural e construtivista, identificar indicadores para políticas públicas, destinadas à formação de educadores ambientais em nível superior, tendo em vista o processo de integração na Região Metropolitana de Curitiba?

Estas hipóteses constituem a diretriz para a continuidade do estudo, para a teorização e etapas restantes.

\section{Teorização}

Nesta etapa, os estudantes sentiram a necessidade de aprofundar o conhecimento, a importância da revisão da literatura e da construção sistematizada do referencial teórico, envolvendo leituras, busca de epistemologia das Ciências Sociais e Humanas (e portanto Pedagógicas) bem como das ciências da natureza.

Juntos, o professor e os alunos selecionaram autores, obras, informações técnicas e científicas, empíricas, oficiais, etc. relacionadas logicamente ao problema e seu contexto. O processo de leitura das obras, de análise, síntese, reflexão crítica, de elaboração, de estudo e pesquisa, avançou em relação aos momentos preliminares. Foi quando se elaborou a Recensão Crítica, tendo sido discutida em articulação com o Seminário Interdisciplinar. O processo de diálogo, a heterogeneidade do grupo, propiciaram a interação das áreas de conhecimento diversas, predispondo as pessoas à produção de novos saberes. A discussão na perspectiva da ação-reflexão-ação, e a dinâmica de interações, desencadeada por esta prática interdisciplinar, permitiu a construção e reconstrução dos conhecimentos.

A compreensão da Metodologia da Problematização e das técnicas, Recensão Crítica e Seminário Interdisciplinar, como prática do processo pedagógico, a operacionalização de idéias, os novos modos de aprendizado e de (re) construção de saberes vividos, levaram todos a uma participação efetiva na prática, conseguindo assim, produzir saberes verificados nas sínteses produzidas ao final do seminário interdisciplinar.

Estes conhecimentos, "ainda devem ser aprofundados no confronto com a própria experiência e com as reflexões dos epistemólogos a respeito" (MEDINA, 1994). As interrelações histórico-sociais e o conhecimento científico, como social da humanidade estão embutidas nas reflexões e elaboração como construção social da humanidade estão embutidas nas reflexões e elaboração do referencial teórico. Temos sempre presente que o papel fundamental da interdisciplinaridade, em nível das ciências que permitem a construção de novas formas de perguntas, remetem a um esboço de problemáticas de pesquisa provindas de olhares diferentes, que oferecem possibilidades de trocas, de criação e de produção de conhecimento coletivo por meio das interações no contexto da abordagem socioambiental.

\section{Recensão crítica}

As intenções de teses individuais, que privilegiaram práticas educativas ambientais, levaram os estudantes a uma análise e reflexão de obras escolhidas, elaborando uma recensão crítica individual, apresentada e discutida coletivamente no Seminário Interdisciplinar.

A Recensão Crítica é a redação de um trabalho acadêmico que se caracteriza por um conjunto de atividades teórico-práticas que permitem ao estudante, individual, ou coletivamente, a análise bibliográfica, o conhecimento crítico e mais aprofundado da obra de um autor, e de suas idiossincrasias, tendo em vista o problema em estudo para o qual se necessita a revisão de literatura, seja em vista de uma dissertação ou de uma tese.

O professor enfatizava ao grupo os objetivos, a atitude e a técnica para a leitura das obras e elaboração da recensão. O estudante era estimulado a uma leitura atenta, à reflexão crítica, à operacionalização de idéias, à organização de síntese e comentários sistematizados, conforme os seguintes procedimentos:

- identificação da obra; credenciais do autor; quadro de referências e metodologia do autor; pressupostos e resumo da obra; conclusões do autor; quadro de referências e crítica do resenhista;

- abstract;

O Seminário que segue é a dinâmica que deu vida à recensão; é o momento do desencadear das interfaces da possível reconstrução do conhecimento.

A problematização, presente em todas as etapas, articula as duas técnicas, o que significa que a Recensão Crítica e o Seminário Interdisciplinar estão ambos inseridos na Metodologia da Problematização.

\section{O seminário interdisciplinar}

Uma das características desta prática interdisciplinar de ensino e pesquisa que vimos construindo, é que não se exige a renúncia, por parte de cada profissional, de seu 
saber específico (o biólogo seguirá sendo biólogo; o sociólogo, sociólogo e assim por diante); espera-se que o olhar de cada saber informe o coletivo de percepções e intuições próprias a cada um dos saberes presentes, para que, no momento seguinte, sejam-lhe devolvidos outros olhares diferentes. Assim, o agrônomo, o geógrafo, o sociólogo, o biólogo, etc., em cada um de seus saberes projetará seu próprio olhar da realidade e receberá dos outros, aquilo que, por si próprio, era menos capaz de perceber. Esta troca se dá em diversas instancias: teóricas, empíricas, metodológicas, conceptuais etc. (FLORIANI, 1998).

Nesta etapa, um conjunto de atividades psicosociopedagógicas foram vividas, com base nas relações sociais e interpessoais assim como nas ideossincrasias de cada um e do grupo. As idéias de cada qual, a reflexão, a observação, a crítica, a comunicação, a ação, permitiram que "as interrelações fossem analisadas - meio ambiente natural versus meio ambiente artificializado - pelas práticas sociais e humanas" (FLORIANI, 1998), incluindo práticas sociais de Educação Ambiental.

As atividades do Seminário Interdisciplinar, sucintamente, consistiram em:

- introdução;

- apresentação da recensão pelo resenhista; seguem as fases de sabatina, simpósio, de mesa redonda, de explicações pessoais do resenhista, debate e discussão crítica de problemas pertinentes ao conteúdo em questão;

- avaliação crítica e contribuições pelo coordenador; ao final,

- elaboração de síntese individual e posterior construção coletiva.

É da dinâmica das interações e da reelaboração de conteúdos, que resulta a reconstrução do conhecimento, na articulação dos saberes diferenciados. $\mathrm{O}$ aprofundamento das interrelações nos distintos níveis de saberes construídos nas dinâmicas do próprio Seminário, deu-se pela participação de todos, estudantes e docentes, também nas Oficinas de Pesquisa periodicamente realizadas.

Percebemos então, que na prática interdisciplinar constroem-se e reconstrõem-se saberes sem, no entanto, podermos precisar o instante exato em que ela acontece, e nem poder-lhe atribuir "um status seguro e consagrado", segundo FLORIANI (1997), pois a prática interdisciplinar é "um processo multidisciplinar que busca constituir a interdisciplinariedade" (MEDINA, 1996).

Desta forma, a prática interdisciplinar exige um método de abordagem da realidade, no caso, foi adotada a Metodologia da Problematização, que pressupõe uma lógica de procedimentos sucessivos que partem da realidade e retornam a ela, reconstruindo-a.

No caso em pauta, sínteses provisórias foram então construídas logo após ao Seminário. A produção do conhecimento efetivada durante e após o processo, individual e coletivamente, veio colaborar para a fundamentação do problema-objeto de pesquisa, especialmente quanto aos aspectos da Educação Ambiental.

\section{Hipóteses de solução}

$\mathrm{Na}$ continuidade dos processos de ensino e de pesquisa, a busca de informações e a teorização, até aqui, serviram de fundamento para modos inovadores de pensar e agir em prol de produção do conhecimento, para incitar a superação das problemáticas em estudo, estruturando hipóteses de solução para o cotidiano concreto.

Nas oficinas ocorreram a formulação de uma ou mais hipóteses que apontaram para um dimensionamento viável, bem como à elaboração de instrumentos para a busca de soluções, relacionadas aos problemas de estudo.

Teoria e prática devem caminhar juntas para o aprofundamento e consistência da pesquisa. Assim foram surgindo temáticas centrais relacionadas ao meio ambiente e ao desenvolvimento da Região Metropolitana da Curitiba. As problemáticas se referiam aos recursos naturais e energéticos como ar, água, madeira, minerais, etc. e aos problemas sociais como saúde, educação, degradação ambiental, e ao desenvolvimento mal proposto, à pobreza, etc.

Assim, é nítida a complexidade entre os dois sistemas: sistema-natureza e sistema-sociedade, cujo estudo e pesquisa ao serem realizadas, constituíram fundamentos para teses no Curso de Doutorado em Meio Ambiente e Desenvolvimento, já defendidas. ${ }^{8}$

8 Entre outras as de: CARNEIRO, M. S. A dimensão ambiental da educação escolar de $1^{a}$ a $4^{a}$ séries do ensino fundamental na escola pública, na cidade de Paranaguá. Curitiba. 1999. Tese (Doutorado em Desenvolvimento e Meio Ambiente), Universidade Federal do Paraná.

COSTA, M. L. Organizações de bairros: história e práticas comunitárias que possam levar a sustentabilidade do meio na cidade de Paranaguá e Ilha dos Valadares. Curitiba. 1999. Tese (Doutorado em Desenvolvimento e Meio Ambiente), Universidade Federal do Paraná.

LUZ, F. G. Formação de formadores em educação ambiental nos cenários da região metropolitana de Curitiba. Tese (Doutorado em Desenvolvimento e Meio Ambiente), Universidade Federal do Paraná. 2001. 


\section{Aplicação na realidade}

Esta etapa é destinada à prática social e prática política segundo Fourez (1995), na realidade propriamente dita. Possibilita a intervenção, o manejo de situações relacionadas à solução dos problemas ambientais por meio dos indicadores encontrados no estudo, elementos básicos para a construção de políticas públicas e, portanto, para ações futuras.

No caso do Doutorado, em foco a prática interdisciplinar, os estudos e pesquisas, e também as teses - cujos saberes continuam em construção, acreditamos, alcançarão, por certo, o nível de indicação das políticas públicas para solução de problemas.

Os estudos e práticas ainda estão acontecendo. Consideramos que na aplicação, o confronto é com o real em movimento, dinâmica e interativamente construído com os elementos do meio ambiente, onde o pensado se transforma em prática; onde se aprende a pensar a unidade teoriaprática, onde a dialética de ação - reflexão e ação é possibilitada e exercida (BERBEL, 1996), no sentido de ampliar as possibilidades da prática política, social e educativa e superação dos limites.

Cremos ter sido possível aos leitores perceberem, neste relato, que a continuidade do processo nas práticas interdisciplinares iniciadas nas oficinas passa a acontecer também nas dinâmicas interativas da disciplina Educação Ambiental; que a busca de respostas às questões levantadas não se esgota aqui; muitas das questões serão objeto de outro artigo, que incluirá a abordagem sobre a formação do educador ambiental.

\section{Algumas considerações finais}

Como em todo campo em construção, o campo da educação voltada ao meio ambiente e desenvolvimento projeta, nos dias atuais, para o ensino e a pesquisa, um novo espaço conceitual e metodológico.

Não obstante aos avanços apresentados nos fóruns de discussão promovidos nos diferentes países, inclusive na América Latina, as iniciativas e os resultados deveriam ser mais aproveitados nas universidades e nos órgãos estatais.

Assim, um conjunto de fatores de ordem cultural política, social, econômica e pedagógica, têm que ser considerados, para nos introduzirmos no terreno da inovação educacional, que exige estudo e pesquisa permanentes.
A abordagem, no presente artigo, considerou duas dimensões sobre as quais construímos as reflexões e a prática pedagógica interdisciplinar vivenciada: uma dimensão teórico-epistemológica e outra metodológica, pois ambas fazem parte de um novo aprender-ensinar-fazer, no âmbito da relação natureza/cultura humana.

Na primeira dimensão, teórico-epistemológica, tivemos a intenção de mostrar a necessidade de problematizar um novo saber-fazer sobre as questões socioambientais que não podem ser percebidas e entendidas isolada e separadamente umas das outras. Trata-se de um paradigma em construção e pode ser entendido, lido e olhado de múltiplas maneiras.

Quanto à segunda dimensão, a metodológica, consideramos que:

a) embora a referência seja a uma situação concreta (turma II) de prática interdisciplinar, é interessante deixar claro que não se tratou de explorar aqui o processo metodológico em si (do Curso de Doutorado em Meio Ambiente e Desenvolvimento da UFPR) mas de explicitar que, integradamente a este, à teoria, às oficinas de pesquisa, às problemáticas e demais disciplinas, a Educação Ambiental, interagindo na totalidade do processo, utilizou em sua prática interdisciplinar, a Metodologia da Problematização, os procedimentos metodológicos a ela inerentes e o Seminário Interdisciplinar, como alternativa metodológica integradora e inovadora, e que, ainda em fase inicial, apresentou resultados animadores;

b) restrições houve, sim, e muitas, a começar pelas resistências aos trabalhos interdisciplinares (dinâmicas) que exigem atitude interdisciplinar, compromisso, frequiência dos participantes (parceria) na construção coletiva de conhecimento; resistência aos procedimentos pedagógicos inovadores, apesar de alguma eficácia no campo disciplinar, foi de todo modo percebido que o processo tradicional é insuficiente para dar conta desta nova tarefa educativa; dificuldades na opção de leituras para definir um referencial teórico pertinente, atual, com credibilidade; fragilidades e contradições em aspectos dos textos de base legal, construídos ideologicamente, com funções apenas reprodutivistas e conservacionistas do sistema capitalista; restrições de tempo, carga horária reduzida à disciplina Educação Ambiental, impe- 
diram um estudo mais aprofundado dos conteúdos e sobre a avaliação da prática, não sendo possível chegar a curto prazo, a uma prática políticoeducativa de intervenção;

c) quanto as possibilidades da prática interdisciplinar ser exercitada, podemos sinalizar vários momentos: nas dinâmicas interativas no interior das disciplinas e também da Educação Ambiental com os demais saberes, nas oficinas, seminários etc. Desencadearam-se: a reflexão-crítica aos saberes ambientais, aos documentos legais, às práticas ambientais apenas reproduzidas; sínteses provisórias de conhecimentos foram elabo- radas para um projeto de integração de conhecimentos diferenciados sobre as problemáticas construídas interdisciplinarmente.

Finalmente, esclarecemos que esta prática está no início ainda; com certeza, será necessário romper certas reações conservadoras dos isolamentos disciplinares, reconhecendo todavia que o papel dos especialistas, sejam eles profissionais de meio ambiente ou educadores ambientais, é imprescindível.

Esse, pois, foi um exercício de interdisciplinaridade possível de ser vivido.

\section{REFERENCIAS}

BERBEL, N. A. N. Metodologia da problematização: uma alternativa metodológica apropriada para o ensino superior. Semina, Londrina, Vel, 1994. Edição especial.

Metodologia do Ensino Superior. São Paulo: Papirus, 1994.

BORDENAVE, J. D.; PEREIRA, A. M. Estratégias de ensino aprendizagem. 4. ed. Petrópolis: Vozes, 1982.

CARNEIRO, S. C. A dimensão ambiental da educação escolar na rede escolar pública de Paranaguá. Curitiba, 1999. Tese (Doutorado) - Universidade Federal do Paraná.

FAZENDA, I. Integração Interdisciplinar no ensino brasileiro. São Paulo: Loyola, 1979.

Interdisciplinaridade: história, teoria e pesquisa. São Paulo: Papirus, 1994.

Interdisciplinaridade: um projeto em parceria. São Paulo: Loyola, 1991.

FLORIANI, D. Interdisciplinaridade: teoria e prática de pesquisa e do ensino no Doutorado em Meio Ambiente e Desenvolvimento (UFPR). Curitiba: UFPR, 1997/99.

FREIRE, P. Conscientização: teoria e prática da libertação. Uma introdução ao pensamento de Paulo Freire. 3. ed. São Paulo: Moraes, 1980.

FOUREZ, G. A Construção das Ciências. São Paulo: Unesp, 1995.

GONZÁLEZ GAUDIANO, E. Educación ambiental. México: Sistemas Técnicos de Edición, 1997.
HOBSBAWN, E. Era dos Extremos: o breve século XX 1914-1991. São Paulo: Companhia das Letras, 1995.

LEFF, E. Sociologia y ambiente: sobre el concepto de racionalidad ambiental y as transformaciones del conocimiento. In: VIEIRA, P. F.; MAIMON, D. (Org.). As ciências sociais e a questão ambiental: rumo à interdisciplinaridade. Rio de Janeiro: APED (Associação de Pesquisa e Ensino em Ecologia e Desenvolvimento); Belém: Universidade Federal do Pará, 1993. p. 95-130.

LUCK, H. Pedagogia interdisciplinar. 2. ed. Petrópolis: Vozes, 1994.

LUDKE, M.; ANDRÉ, M. E. D. A. Pesquisa em educação: abordagens qualitativas. São Paulo: Pedagógica e Universitária, 1986.

MACHADO, N. J. Epistemologia e didática. São Paulo: Cortez, 1995.

MEDINA, N. M. Elementos para introdução da dimensão ambiental na educação escolar. Brasília: UFMT, 1994.

MENDONÇA, F. et al. Gestão ambiental e condições de vida na cidade. Curitiba: MAD - UFPR, 1996.

PIAGET, J. Estudos Sociológicos. Rio de Janeiro: Nova Fronteira, 1975.

RADCLIFF-BROWN, P. D. Estudos de organização social. São Paulo: USP, 1975.

REIGOTA, M. et al. Tendências da educação ambiental no Brasil. [S. 1.]: Edunisc, 1998. 
KNECHTEL, M. R. Educação Ambiental: uma prática interdisciplinar

UNESCO. Artigo 5, letra a. In: CONFERÊNCIA MUNDIAL DE EDUCAÇÃO SUPERIOR, 1998, Paris. Anais... Paris: [s.n.], 1998.

VASQUEZ, A. S. Filosofia da práxis. 4. ed. Rio de Janeiro: Paz e Terra, 1977.

VYGOTSKI, L. A formação social da mente. São Paulo: Martins Fontes, 1988.
WACHOWICZ, L. et al. A interdisciplinaridade na universidade. Curitiba: Champagnat, 1998.

WEIL, P. et al. Rumo à nova transdisciplinaridade. São Paulo: Summus, 1993. 